\title{
Statistical Analysis of Common Diseases of College Students According to Different Grades
}

\author{
Hongjun Teng ${ }^{1, a^{*}}$, Zhenbo Bao ${ }^{2, b}$, Hongying Sun ${ }^{2, c}$ and Yu Shi ${ }^{2, d}$ \\ ${ }^{1}$ Clinic, Tianjin Agricultural University, Tianjin, China, 300384 \\ ${ }^{2}$ Engineering and Technology College, Tianjin Agricultural University, Tianjin, China, 300384 \\ a*hongjun-teng@163.com, bbaozhenbo@sohu.com, 'sunn@tjau.edu.cn, dsyych83@tjau.edu.cn
}

Keywords: College students; Common diseases; Different grades; Statistical analysis

\begin{abstract}
In order to provide basis for medical and health care, the statistical analysis was made on the outpatient visits of the students in grade 2 to 4 in Tianjin Agricultural College from September to December in 2016. The 10 common diseases of colds, upper respiratory tract infection, excessive internal heat, sprain, gastroenteritis, skin irritation, toothache, stomachache, and bronchitis and eye fatigue were analyzed statistically, it found that the incidence of colds, upper respiratory tract infections and excessive internal heat were higher; the incidence of common diseases tended to decrease with the growth of grade. The incidence of upper respiratory tract infection, sprain, stomachache and bronchitis of second grade was higher than that of the third grade and fourth grade, and the incidence of colds, excessive internal heat and skin irritation of fourth-grade was lower than the second and third grade; the reasons are that the low grade students have low self-living ability, lack of health care knowledge, and low immune function. Due to senior students facing heavy academic, PG entrance exam and other academic pressure, the incidence of eye fatigue was higher. Health care workers should adopt appropriate health education measures to improve the health level of college students.
\end{abstract}

\section{Introduction}

College students are the important resources of scientific and technological progress and social development, and the backbone of the future national construction. The health of college students is the premise and basic guarantee for their successful completion of their studies and healthy growth [1-3]. It is an important task of education to improve the students' physical health, to promote the healthy growth of students is the starting point and the foothold of all the educational work. The health of university students reflects the comprehensive development level of politics, economy, culture and health [4-6]. At present, the physical health of college students are affected by various common diseases and other factors, and their health status is not optimistic; the health of college students has become the focus of attention of the whole society. To improve the health of college students requires the university medical and health care workers to take reasonable and feasible measures to actively prevent and treat common diseases in college students [7-10]. Combined with long-term medical and health care in colleges and universities, from September 2016 to December 2016, the common diseases of college students in Tianjin Agricultural College were analyzed statistically. From the different grades, the distribution of common diseases in college students and the main reasons are analyzed, which can provide information for better preventive health care and health education, promote students to master the disease prevention and health knowledge, and provide some help for the successful completion of academic and healthy growth of college students.

\section{Statistical Analysis of Common Diseases of College Students}

In the outpatient treatment work, from September 2016 to December 2016, the statistical analysis was made on the disease situation of grade 2 to 4 students of Tianjin Agricultural College, a total of 616 people for the analysis of the object. The return visits were not within the scope of statistics, of which 239 were male students, 377 female students in the age of 18-25 years, in 2-4 grades. The 10 
kinds of common diseases of college students are colds, upper respiratory tract infections, excessive internal heat, sprain, gastroenteritis, skin irritation, toothache, stomach pain, bronchitis and eye fatigue, the distribution of numbers and percentage are shown in Table 1.

Table 1 Numbers and proportion of the 10 kinds of common diseases of college students

\begin{tabular}{|c|c|c|c|c|c|c|c|c|}
\hline \multirow{3}{*}{$\begin{array}{c}\text { No. } \\
1 \\
\end{array}$} & \multirow{3}{*}{$\begin{array}{l}\text { Name } \\
\text { Colds }\end{array}$} & \multirow{3}{*}{$\begin{array}{c}\text { Numbers } \\
213\end{array}$} & \multicolumn{6}{|c|}{ Numbers and proportion } \\
\hline & & & \multicolumn{2}{|c|}{ Sophomore } & \multicolumn{2}{|c|}{ Junior } & \multicolumn{2}{|c|}{ Senior } \\
\hline & & & 81 & $13.15 \%$ & 81 & $13.15 \%$ & 51 & $8.28 \%$ \\
\hline 2 & $\begin{array}{l}\text { Upper respiratory } \\
\text { tract infections }\end{array}$ & 91 & 47 & $7.63 \%$ & 22 & $3.57 \%$ & 22 & $3.57 \%$ \\
\hline 3 & $\begin{array}{c}\text { Excessive internal } \\
\text { heat }\end{array}$ & 78 & 34 & $5.52 \%$ & 34 & $5.52 \%$ & 10 & $1.62 \%$ \\
\hline 4 & Sprain & 45 & 24 & $3.90 \%$ & 12 & $1.95 \%$ & 9 & $1.46 \%$ \\
\hline 5 & Gastroenteritis & 43 & 20 & $3.25 \%$ & 12 & $1.95 \%$ & 11 & $1.79 \%$ \\
\hline 6 & Skin irritation & 40 & 17 & $2.76 \%$ & 17 & $2.76 \%$ & 6 & $0.97 \%$ \\
\hline 7 & Toothache & 38 & 14 & $2.27 \%$ & 15 & $2.44 \%$ & 9 & $1.46 \%$ \\
\hline 8 & Stomach pain & 25 & 13 & $2.11 \%$ & 6 & $0.97 \%$ & 6 & $0.97 \%$ \\
\hline 9 & Bronchitis & 23 & 9 & $1.46 \%$ & 5 & $0.81 \%$ & 9 & $1.46 \%$ \\
\hline 10 & Eye fatigue & 20 & 4 & $0.65 \%$ & 4 & $0.65 \%$ & 12 & $1.95 \%$ \\
\hline & Total & 616 & 263 & $42.72 \%$ & 208 & $33.78 \%$ & 145 & $23.5 \%$ \\
\hline
\end{tabular}

Among the 616 cases of Tianjin Agricultural College students, 263 cases, 208 cases, 145 cases are 2,3 and 4 grade college students respectively, the proportion of the second, third and fourth grade are $42.72 \%, 33.78 \%$ and $23.5 \%$ respectively. Basing the statistical data as shown in Table 1, can obtain such a conclusion that the incidence of common diseases shows a decreasing trend with the higher grade of college students, the main reasons for this are that the low-grade students to adapt to the environment are not strong, and self-care ability are weak. It also can conclude that the high proportions of common diseases are colds, upper respiratory tract infections and excessive internal heat, which was caused by the cold season and dry climate; in addition, students eat less vegetables and fruits.

\section{Statistical Analysis of 8 Common Diseases among College Students According to Different Grades}

According to the different grades, the proportions of distribution of the 8 kinds of common diseases are shown with the bar chart in Figure 1 to Figure 8, the incidence of colds in grade 2, grade 3 and grade 4 were $13.15 \%, 13.15$ and $8.28 \%$, and the incidence rates of excessive internal heat were $5.52 \%, 5.52 \%, 1.62 \%$, and the incidence rates of skin irritation were $2.76 \%, 2.76 \%$ and $0.97 \%$, respectively; the following conclusions were obtained: the incidence of colds, excessive internal heat and skin allergies among university sophomore, junior students, are significantly higher than senior students; sophomore and junior students there is no difference between. The main reason for this is: low grade students of small age, poor immune function, self-care and prevention of disease knowledge deficiencies. The incidence of upper respiratory tract infection in grade 2, grade 3 and grade 4 were $7.63 \%, 3.57 \%$ and $3.57 \%$, and the incidence rates of sprain were $3.90 \%, 1.95 \%, 1.46 \%$, and the incidence rates of gastroenteritis were $3.25 \%, 1.95 \%$ and $1.79 \%$, and the incidence rates of stomach pain were $2.11 \%, 0.97 \%$ and $0.97 \%$, respectively; the reasons for the statistical conclusions is that low grade students of small age, self-care and prevention of disease knowledge deficiencies. Due to academic stress and pressure from postgraduate examination of senior students, the incidence of eye fatigue was higher than that of junior and sophomore students, with the incidence rates of $1.95 \%, 0.65 \%$ and $0.65 \%$, respectively. 


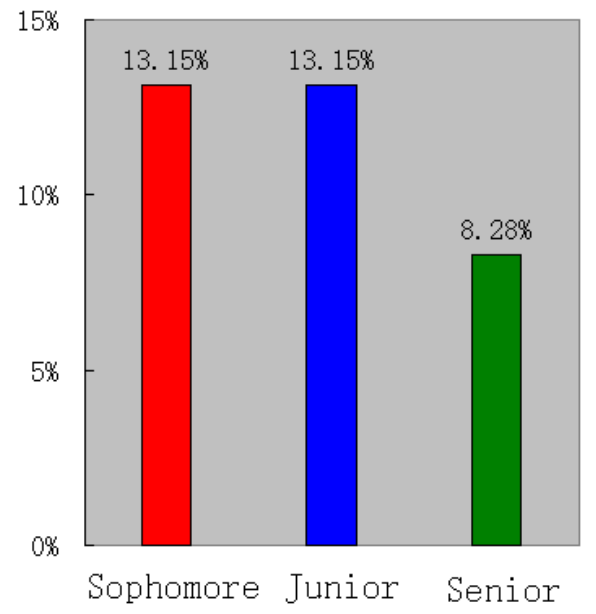

Figure 1. The distribution proportion of colds according to different grades

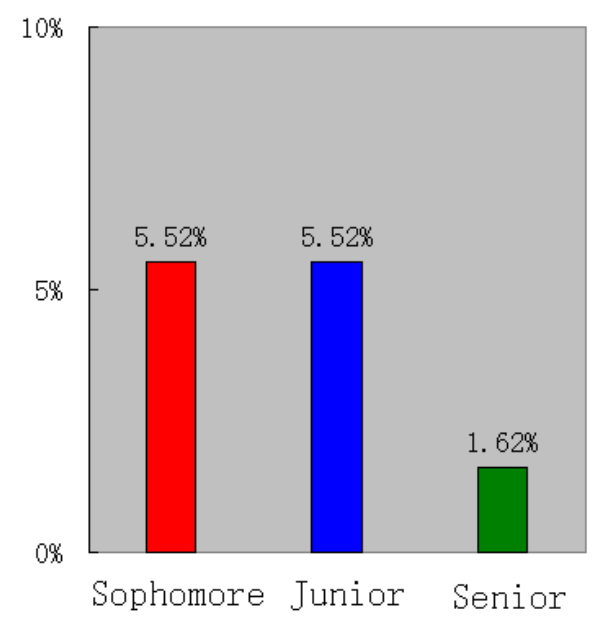

Figure 3. The distribution proportion of excessive internal heat according to different grades

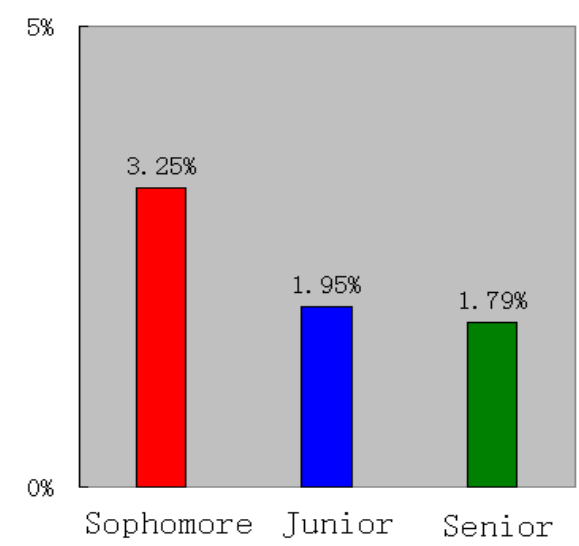

Figure 5. The distribution proportion of gastroenteritis according to different grades

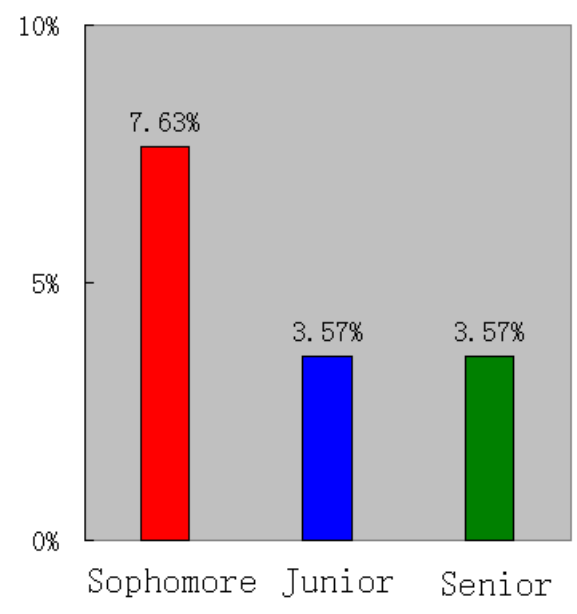

Figure 2. The distribution proportion of upper respiratory tract infection according to different grades

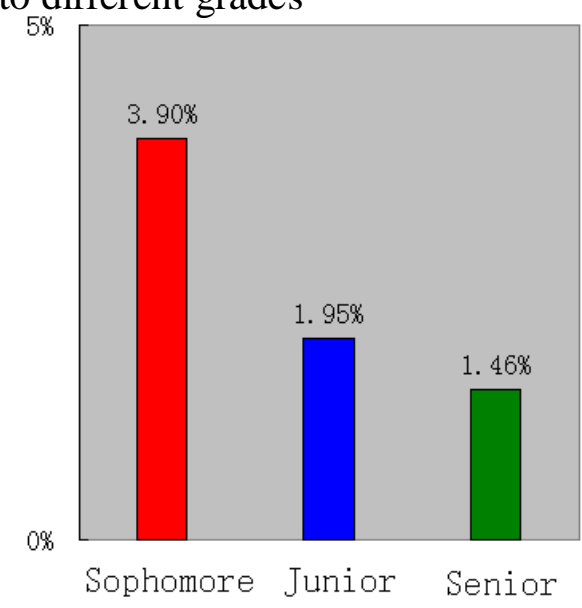

Figure 4. The distribution proportion of sprain according to different grades

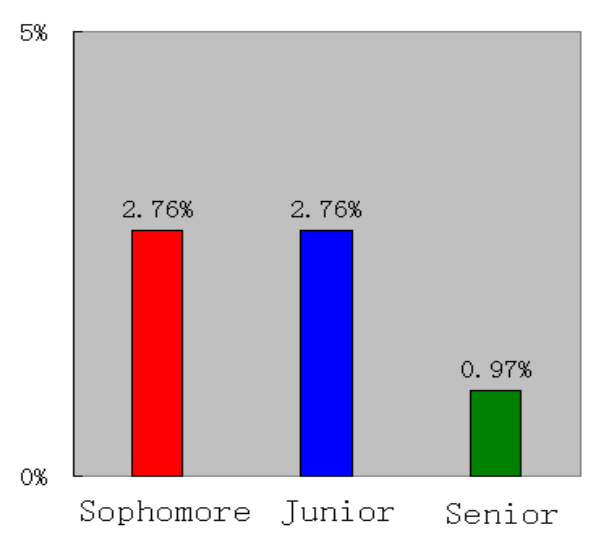

Figure 6. The distribution proportion of skin allergies according to different grades 


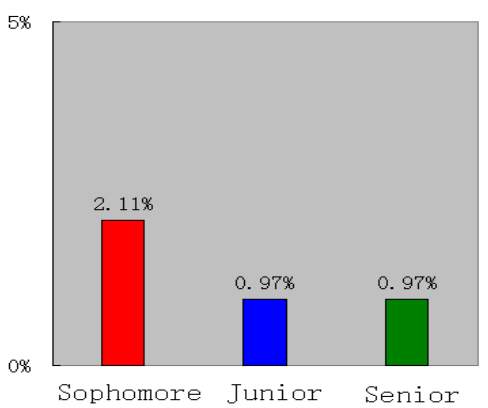

Figure 7. The distribution proportion of stomach pain according to different grades

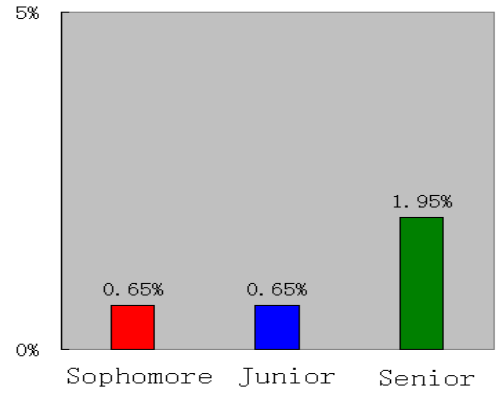

Figure 8. The distribution proportion of eye fatigue according to different grades

\section{Summary}

Through the statistical analysis of common diseases of college students in Grade 2 to Grade 4 of Tianjin Agricultural College in autumn and winter, it was found that the incidence of colds, upper respiratory tract infection and excessive internal heat was higher. It is also found that the common diseases of college students tend to decrease with the growth of grade; the incidence of upper respiratory tract infection, sprain, stomachache and bronchitis was higher than that of the third grade and fourth grade, and the incidence of colds, excessive internal heat, skin irritation, fourth-grade college students was lower than the second and third grade, the reasons are that the low grade students have low self-living ability, lack of health care knowledge, and low immune function. The high incidence of eye fatigue in the fourth grade students is due to senior students face heavy academic, PG entrance exam and other academic pressure. It is suggested that Health care workers should adopt appropriate health education measures to improve the health level of college students.

\section{Acknowledgements}

This work was financially supported by the Project of Tianjin Agricultural University Education and Teaching Reform Research (2016-A-04).

\section{References}

[1] W.Y. Yan, X.M. Jia: For all Health, Vol. 10 (2016) No.15, p.8.

[2] Q.B. Wang, X. Shi and Y.Y. Wei: China Medical Herald, Vol. 6 (2009) No.26, p.120.

[3] X.C. Sun: China Medical Engineering, Vol. 19 (2011) No.12, p.149-150.

[4] W.J. Liu: Journal of Guangdong University of Petrochemical Technology, Vol. 23 (2013) No.5, p.35-37.

[5] Z,H, Lu: Journal of Qiqihar University of Medical, Vol. 36 (2015) No.11, p.1664-1665.

[6] S.F. Wang, L.Z. Xu and J. Fang: Chin J Sch Health, Vol. 28 (2007) No.7, p.609-610.

[7] P.H. Wang: Journal of Anhui Institute of Education, Vol. 25 (2007) No.6, p.89-92.

[8] Y.H. Feng, M.Y. Wu and H.L. Chen: Journal Traditional Medicine Management, Vol. 24 (2016)

[9] No.10, p.167-169.

[10] S.M. Sun: Chin J Sch Health, Vol. 35 (2014) No.11, p.1739-1741.

[11]Q.T. Wu, J.W. Gan: Health Medicine Research and Practice, Vol. 12 (2015) No.5, p.86-88. 